\title{
Analysis of the reservoir yield evaluation indices
}

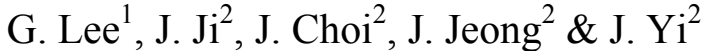 \\ ${ }^{1}$ Korea Institute of Water and Environment, \\ Korea Water Resources Corporation, South Korea \\ ${ }^{2}$ Department of Civil and Transportation Engineering, \\ Ajou University, South Korea
}

\begin{abstract}
The number of countries experiencing water shortages due to increasing water demands as the population grows and industry expands is increasing. Water demands in South Korea have also been increasing steadily due to rapid economic growth over the past 50 years. To solve this problem, many multipurpose reservoirs have been constructed and used in South Korea's major streams since 1960. However, since downstream water demands have increased consistently due to the expansion of agricultural facilities, the need to prevent water pollution and ensure water-friendly environments has become increasingly important. Yet, the risk of water shortages is continuing. Although annual precipitation has been increasing since the end of the $20^{\text {th }}$ century in Korea, the risk of drought during the dry season has also been increasing. In order to solve these problems, additional water supply facilities such as reservoirs are necessary. However, it is difficult to develop them as there are few suitable locations and adverse impacts on the ecosystem. There is also significant community backlash. Therefore, identifying the amount of available water in existing reservoirs is an important task. Reliability, resilience, and vulnerability indices have been widely used to evaluate reservoir yield. However, there are some problems with using these indices. In this study, we investigate and analyze these indices to improve the stability and efficiency of the water yield from reservoirs.

Keywords: water yield, reservoir, drought.
\end{abstract}




\section{Introduction}

The water yield capacity of multi-purpose reservoirs is the quantity of water that can be supplied from the associated reservoirs. Assessing the water yield capacity of reservoirs is an essential factor in establishing yield plans to secure water resources and determine the size of reservoirs. Even though such assessments are carried out when preparing construction plans, it is necessary to reassess water yield according to current downstream water demands and changing river basin environments. These water yield assessments are not only critical for establishing plans for reservoir but also the entire water resources system (Yi and Song [9]). Many methods to determine reservoir capacity using various kinds of hydrological data collected during the planning phase have been employed to assess the reservoir yield. Rippl [6] proposed a method to determine reservoir capacity using flow mass curve; Alexander [2] proposed a method using a discharge recurrence interval and Gamma distribution; and Gould [3] analyzed reservoir capacity by generating synthetic inflow based on stochastic analysis. Additionally, Hardison [4] proposed the generalization of reservoir capacity coupled with a theoretical distribution of annual inflow; Rittima and Vudhivanich [7] assessed the reservoir yield using resiliency and reliability; Srivastava and Awchi [8] assessed the reservoir yield by using linear and dynamic programmings based on the hedging rule and artificial neural networks; and Adeloye [1] proposed a generalized model of reservoir capacity, water yield, and reliability using multiple linear regression analysis and artificial neural networks.

In Korea, firm yield and reliability methods have been adopted as standards to assess the reservoir yield. However, each method has various problems. There are still issues of resiliency and vulnerability that must be overcome, even though these indices are often mentioned as being complementary indices to reliability. It is very difficult to assess the water yield of the water resource system accurately, and many issues need to be resolved through further studies. The purpose of this study is to establish a foundation to resolve the problems of existing water yield methods by analyzing the characteristics and problems of water yield assessment indices.

\section{Review of the assessment safety standards}

\subsection{General indices}

In general, reliability, resiliency, and vulnerability are indices used to assess the water supply capacities of multi-purpose reservoirs. Definitions of the indices follow. The definitions of these indices are proposed by Hashimoto et al. [5] and explained briefly below

\subsubsection{Reliability}

Reliability is defined as the probability of how steadily and stably water is supplied in a given period of time 


$$
\alpha=\operatorname{Prob}\left[\mathrm{X}_{\mathrm{t}} \in \mathrm{S}\right]
$$

Here, $\alpha$ is a reliability and $\mathrm{S}$ is the state of meeting water demand. Reliability is categorized into occurrence reliability, period reliability, and supply reliability depending on the selection of operation unit and assessment unit. Each of these three reliabilities can be expressed as equations (2), (3), and (4) as follows.

$$
\begin{gathered}
\text { occurence reliability }(\%)=\left[1-\frac{\text { No.of water shortage years }\left(T_{S}\right)}{\text { No.of total analys years }\left(T_{n}\right)}\right] \times 100 \\
\text { period reliability }(\%)=\left[1-\frac{\text { No.of water shortage years }\left(T_{S}\right)}{\text { No.of total analys years }\left(T_{n}\right)}\right] \times 100 \\
\text { supply reliability }(\%)=\left[1-\frac{q \text { quantity of yield shortage }\left(Q_{S}\right)}{\text { Quantity of planned } y \operatorname{cield}\left(Q_{p}\right)}\right] \times 100
\end{gathered}
$$

\subsubsection{Resiliency}

Resiliency is an index expressing how rapidly recovery from failure occurs when water demand cannot be met. If failure continues and the recovery is slow, the resiliency index may get lower, and damage from the water shortage can be large even though reliability values are identical. Resiliency can be defined mathematically, as follows.

Assuming that $T_{F}$ is the duration of the failure state, the resiliency of the system can be defined as the reciprocal of $T_{F}$. Assuming the value of $Z_{t}$ equals 1 when water yield is possible and $Z_{t}$ equals 0 when it is not, the equations are expressed as (5) and (6), as follows.

$$
\begin{array}{ll}
Z_{t}=1 & X_{t} \in S \\
Z_{t}=0 & X_{t} \in F
\end{array}
$$

$\left(\frac{1}{n}\right) \sum_{t=1}^{n} Z_{t}$ is the ratio of duration where the system supply is satisfied under the condition where the time variable, $t$, changes from 1 to $\mathrm{n}$. This term has an identical value to the reliability of the system, which can be expressed as equation (7) below.

$$
\lim _{n \rightarrow \infty} \frac{1}{n} \sum_{t=1}^{n} Z_{t}=\alpha
$$

$W_{t}$ is the transition from the satisfaction state to the dissatisfaction state and can be expressed as follows.

$$
\begin{gathered}
W_{t}=1, X_{t} \in S \text { and } X_{t+1} \in F \\
W_{t}=0, \text { otherwise }
\end{gathered}
$$

As a result, the average value of $W_{t}$ equals $\mathrm{p}$, which is the probability of successful water yield at a time of $t$ and the probability of water yield failure at a time of $t+1$. This can be expressed as follows.

$$
\rho=\operatorname{Prob}\left\{X_{t} \in S, X_{t+1} \in F\right\}=\lim _{n \rightarrow \infty} \frac{1}{n} \sum_{t=1}^{n} W_{t}
$$

$\widetilde{T}_{F}$, the average time that a failure state or dissatisfaction state continues during the period of $\mathrm{n}$, can be expressed as follows. 


$$
\tilde{T}_{F}=\frac{A}{B}
$$

where $A$ is the total sum of times when water yield fails, and B is how many times water yield changes from the satisfaction state to the dissatisfaction state. They can be expressed as equation (12) below.

$$
\tilde{T}_{F}=\frac{1}{n} \sum_{t=1}^{n}\left(1-Z_{t}\right)\left(\frac{1}{n} \sum_{t=1}^{n} W_{t}\right)^{-1}
$$

$\widetilde{T}_{F}$, the average duration, has a value close to $\frac{1-\alpha}{\rho}$, as $\mathrm{N}$ approaches to infinity. Therefore, equation (13) shows the length of time the water yield is expected to fail.

$$
\mathrm{E}\left[T_{F}\right]=\frac{1-\alpha}{\rho}
$$

This means the expected average failure time after the failure occurs. Resiliency is defined as the reciprocal of equation (13), as shown below.

$$
\gamma=\frac{\rho}{1-\alpha}=\frac{\operatorname{Prob}\left\{X_{t} \in S \text { and } X_{t+1} \in F\right\}}{\operatorname{Prob}\left\{X_{t} \in F\right\}}
$$

If the number of transitions from satisfaction state $\mathbf{S}$ to dissatisfaction state $\mathbf{F}$ and the number of reverse transitions, $\gamma$ equals the average probability of recovery from the failure in a single time step, expressed as equations (15) and (16) below.

$$
\begin{gathered}
\gamma=\frac{\operatorname{Prob}\left\{X_{t} \in F \text { and } X_{t+1} \in S\right\}}{\operatorname{Prob}\left\{X_{t} \in F\right\}} \\
\gamma=\operatorname{Prob}\left\{X_{t+1} \in S \mid X_{t} \in F\right\}
\end{gathered}
$$

If the failure of $\left(X_{t} \in F\right)$ occurring in the current time step and the success of $\left(X_{t+1} \in S\right)$ occurring in the next time are statistically independent events, the resiliency $\gamma$ becomes $\operatorname{Prob}\left\{X_{t+1} \in S\right\}$.

\subsubsection{Vulnerability}

An index to judge the severity of water shortage is necessary to prepare for the failure of water yield because the damage may differ according to the amount of the shortage of water yield, even though the reliability and resiliency are identical. Vulnerability is the severity of the water shortage when water cannot be yielded stably. It can be expressed as equation (17) below.

$$
v=\sum_{j \in F} s_{j} e_{j}
$$

where $s_{j}$ is a numerical index of severity in the failure state and $e_{j}$ is the probability that the biggest shortage value falls in the continuation of failure period. The focus of this index is not how long the failure of the system continues but how severe it is. 


\subsection{Case studies of safety standards application in Korea}

The main function of reservoirs is to supply water demands. The firm yield is the maximum yield that can be supplied even in the maximum drought period and becomes the standard in general in Korea.

Water supply capability standards indicate the level of stability of the water yield that can meet water demands or the certainty that the determined yield can be supplied. It can be expressed using probability or frequency concepts.

In Korea, standards used in the past to assess the reservoir yield could be classified into firm yield that could supply water even in the worst drought period on record and water supply capability that assessed water yield during a given period of time.

In Korea until the end of the 1970s, the planned reservoirs were usually assessed under condition whereby inflow during the maximum drought period, which is between 1967 and 1968, satisfied future demands fully. In the 1980s, the planned reservoirs were assessed under condition where by the inflows occurred during some 20 years satisfied future demands fully. Since then, reliability standards based on observed data that could permit one year water deficiency during 30 years period.

Because the methods to assess the reservoir yield differ according to reservoirs or design steps, the standards and assessment methods are inconsistent. This makes relative comparisons of the methods difficult. The water supply capability standards applied to multi-purpose reservoirs in Korea are shown in Table 1 below.

Table 1: $\quad$ Safety standards of multi-purpose reservoirs.

\begin{tabular}{|c|c|c|c|c|}
\hline Dam & $\begin{array}{c}\text { Year of } \\
\text { completing }\end{array}$ & $\begin{array}{c}\text { Quantity } \\
\text { of water } \\
\text { supply } \\
\text { (MCM) }\end{array}$ & $\begin{array}{l}\text { Year of } \\
\text { analysis }\end{array}$ & Safety standards \\
\hline $\begin{array}{l}\text { Soyang } \\
\text { gang }\end{array}$ & 1973 & 1,213 & ‘15-’39 & $\begin{array}{l}\text { Increase of low flow } \\
36 \mathrm{~m}^{3} / \mathrm{s}\end{array}$ \\
\hline $\begin{array}{c}\text { Chungj } \\
\mathrm{u}\end{array}$ & 1986 & 3,380 & '66-'83 & Secured 95\% supply \\
\hline $\begin{array}{l}\text { Andon } \\
\mathrm{g}\end{array}$ & 1977 & 926 & '47-’70 & $\begin{array}{l}\text { Condition of low flow } \\
\text { from ' } 67-\text { ' } 68\end{array}$ \\
\hline Imha & 1993 & 497 & ‘63-’83 & $\begin{array}{l}\text { Secured } 100 \% \text { supply } \\
\text { during } 21 \text { years }\end{array}$ \\
\hline $\begin{array}{c}\text { Dae } \\
\text { cheong }\end{array}$ & 1981 & 1,649 & ‘58-’70 & $\begin{array}{l}\text { Secured } 100 \% \text { supply } \\
\text { during } 13 \text { years }\end{array}$ \\
\hline $\begin{array}{l}\text { Yong } \\
\text { darm }\end{array}$ & 1999 & 650 & ‘63-’88 & $\begin{array}{c}\text { Based on years ' } 67 \sim \text { '68 } \\
\text { and ' } 82 \sim ' 83\end{array}$ \\
\hline
\end{tabular}




\section{Problems with existing assessment indices}

\subsection{Problems of reliability}

As explained earlier, the reliability allows failure of the water supply to some extent during the system's entire operation period. This assessment method, however, tends to show that water yield increases and water supply safety decreases as assessment units get shorter in the order of year, month, and 10 days (Table 2).

Table 2: $\quad$ Relationship between water yield capacity and water yield stability according to the assessment unit of safety standards.

\begin{tabular}{ccc}
\hline Assessment unit & Water yield & Water supply safety \\
\hline year & Small & large \\
month & medium & medium \\
days & big & small \\
\hline
\end{tabular}

These differences mean that water yield and water supply safety results may differ according to the decision maker's choice. This is the biggest weakness of the reliability index as an assessment indicator of water yield. Also, this index cannot express water supply failure in terms of volume or duration.

As seen in the case 1 (Figure 1), when failure occurs for 6 years over a 30year analysis period, the reliability of the system is $80 \%$. However, as shown in case 2 (Figure 2), drought damage increases on a large scale when the drought continues for 6 successive years even though the reliability is $80 \%$, same as the case 1 . Since, this index cannot express the failure volume and successive failure duration, the characteristics of basins with reservoirs cannot be described well enough. This also means there is a clear limit in describing reservoir yield with using the reliability index only.

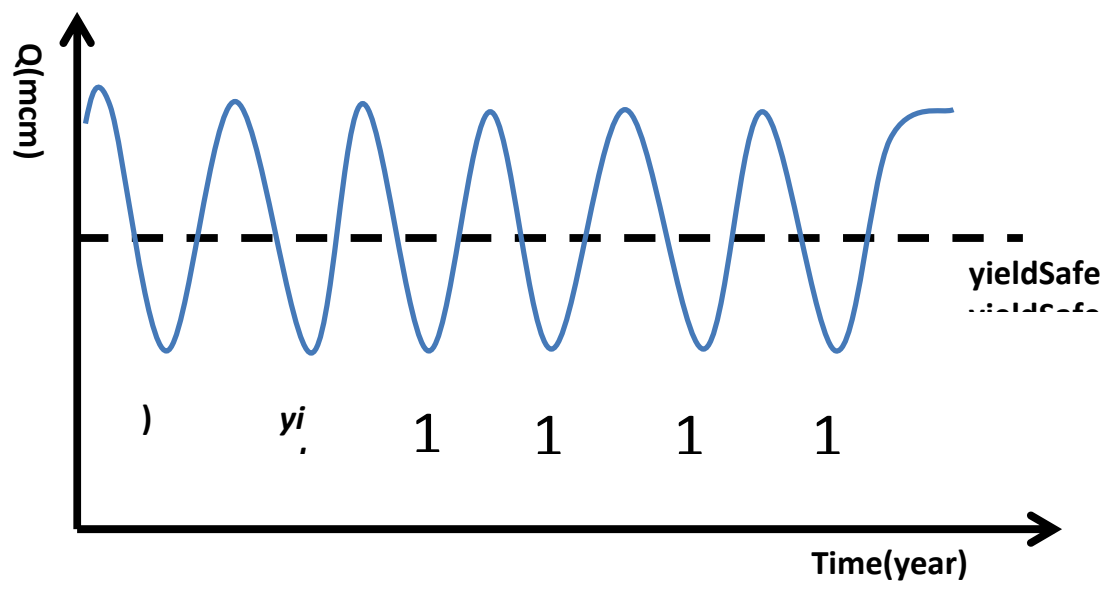

Figure 1: $\quad$ Case 1: water supply capacities. 


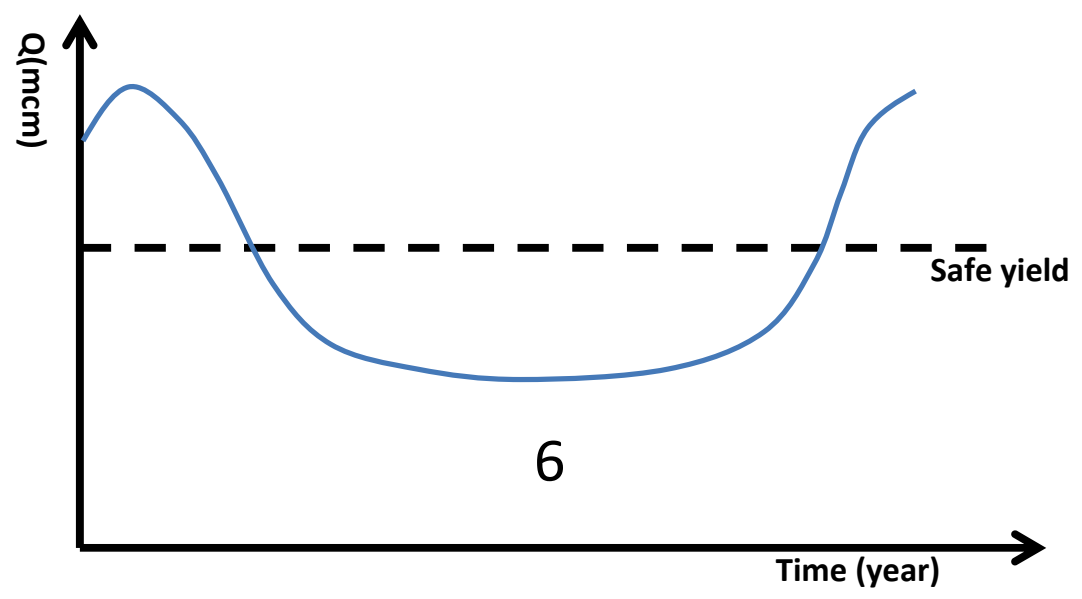

Figure 2: $\quad$ Case 2: water supply capacities.

\subsection{Problems of resiliency}

Resiliency is an index representing how rapidly recovery from failure occurs when water cannot be supplied. The weakness of this index is that the failure proportion during the total failure period cannot be shown, even though it tells how long the failure will continue.

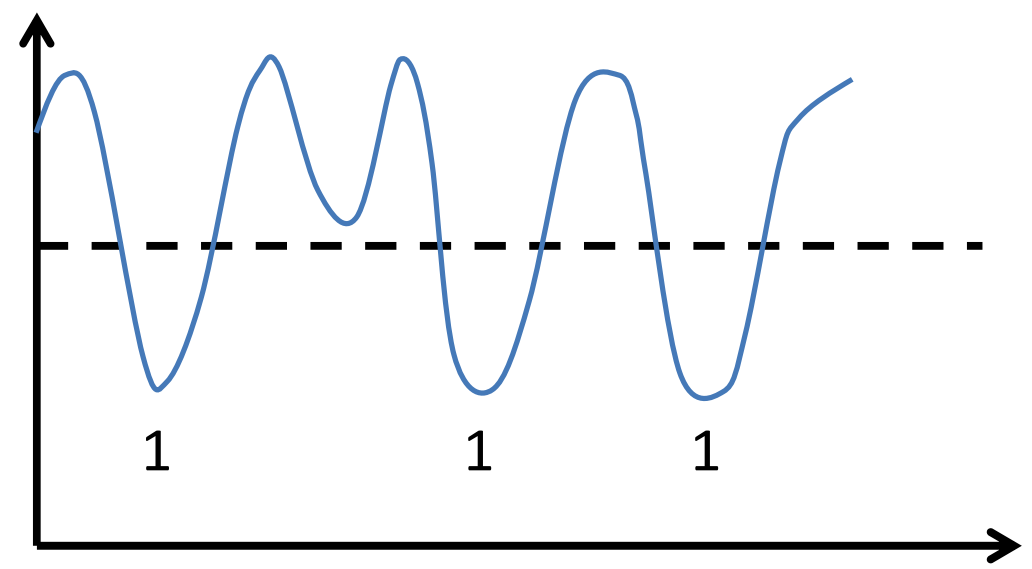

Figure 3: $\quad$ Case 3: water yield capacity. 


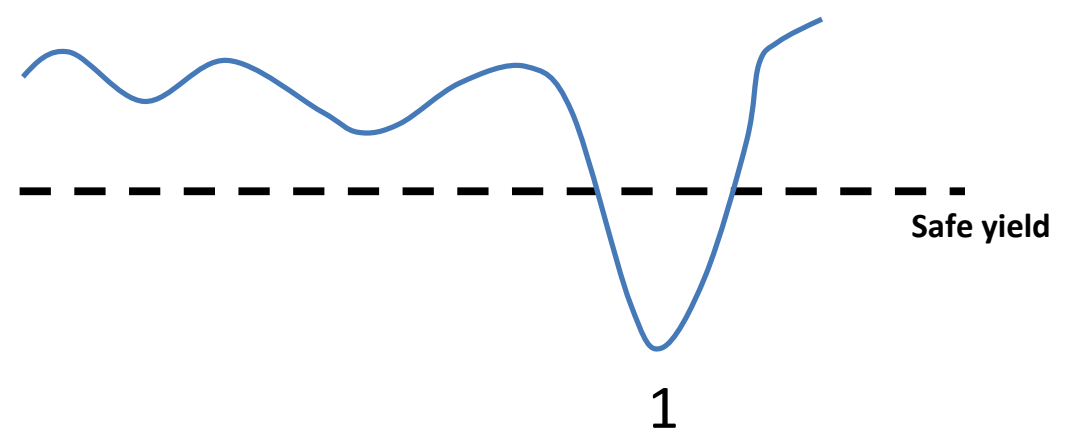

Time(year)

Figure 4: $\quad$ Case 4: water yield capacity.

Especially resiliencies suggested by Hashimoto et al. [5] showed same resilience values although there were 3 years water shortage (Case 3) and 1 year water shortage (Case 4), where reliabilities are $90 \%$ and $97 \%$, respectively for a total period of 30 years.

\subsection{Problems of vulnerability}

Vulnerability means how severe the water shortage is when there is not a stable water supply. This index shows the level of severity when system fails.

As seen in case 5 (Figure 5), the vulnerability can compare the water shortage severities. However, the differences between the two events cannot be recognized when the maximum severity of the water shortage is identical as shown in Figure 6.

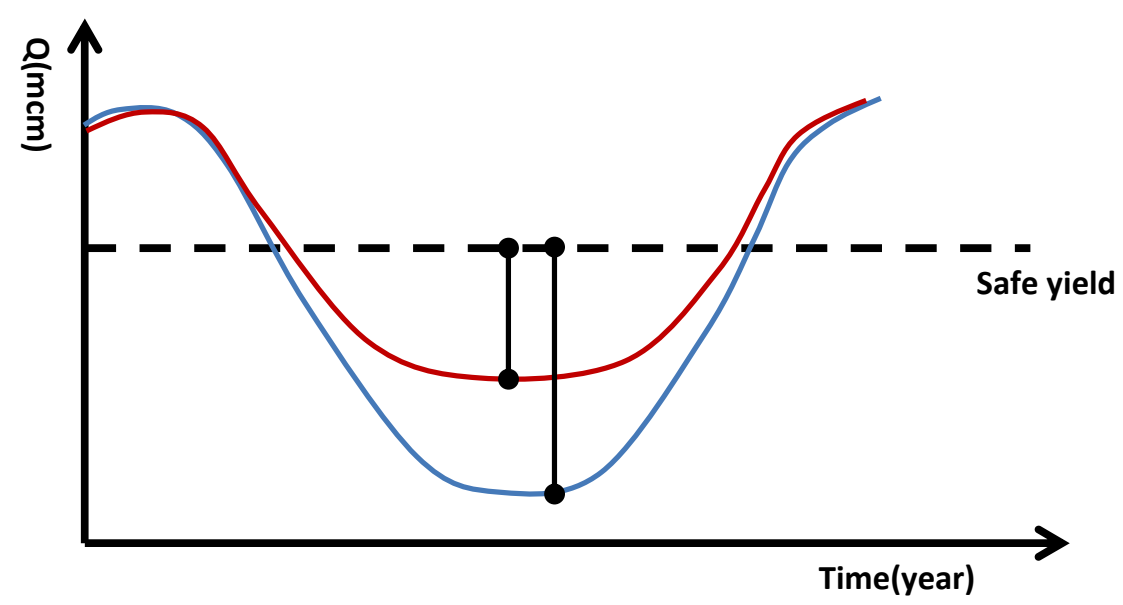

Figure 5: $\quad$ Case 5: water yield capacity. 


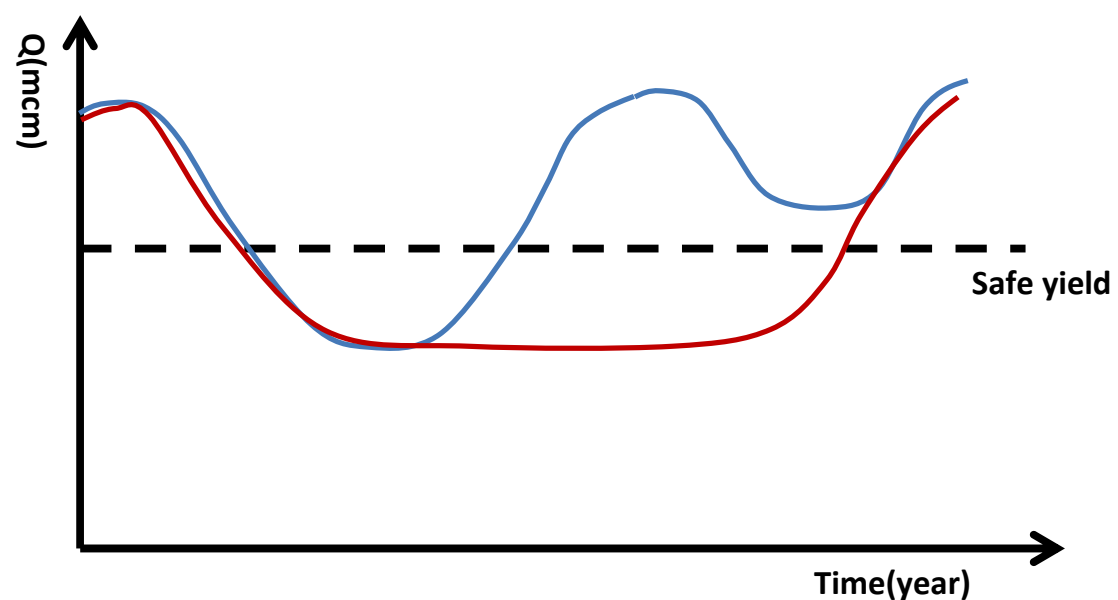

Figure 6: Case 6: water yield capacity.

\section{Conclusions}

Until now, the indices used to assess the reservoir yield in Korea have been firm yield in dry years and reliability. Although assessment based on firm yield in dry years was considered suitable when hydrological data were insufficient in the past. It is however difficult to select the standard dry years and the maximum dry years are totally different for different regions. Also, the data of dry years in the past are not enough to project the future status, so it is not appropriate to accept firm yield in dry years as objective standards.

The advantages of reliability index are the ability to improve overdesign and the inefficient use of water resource facilities associated with the firm yield method. However, this index also has weakness because water yield stability and yield capacity can be different according to assessment unit and drought severity and frequency cannot be determined. Since reliability, resiliency, and vulnerability proposed by Hashimoto et al. [5] are based on statistical concept, there is a limitation in assessing the scale of damage when water shortages exceed water supply capability. Furthermore, the indices of reliability and vulnerability can result in worse water yields, even though the water yield environment improves.

To resolve these problems it is necessary to develop multivariate assessment methods using the existing reliability, resiliency, and vulnerability indices and to develop an experimental water index based on drought damage that has occurred in the past.

Reservoir yield assessment is a complex process that includes social and economic assessments. The aim of this study was to establish a foundation to resolve the problems of existing water yield methods by analysing the characteristics and problems of water yield assessment indices. It is necessary to 
develop objective and integrated indices to assess reservoir yield to ensure a more secure water supply.

\section{Acknowledgement}

This work was supported by a National Research Foundation of Korea (NRF) grant funded by the Korean government (MEST) (No. 2012-0008716)

\section{References}

[1] Adeloye A.J., Multiple Linear Regression and Artificial Neural Networks Models for Generalized Reservoir Storage-Yield-Reliability Function for Reservoir Planning. Journal of Hydrologic Engineering, 14(7), pp. 731-738, 2009.

[2] Alexander, G. N., The use of the Gamma distribution in estimating regulated output from storages. Civil Engineering Transactions, The Institution of Engineers, 4(1), pp. 29-34, 1962.

[3] Gould, B.W., Statistical methods for estimating the design capacity of dams. Journal of the Institution of Engineers, 33(12), pp. 405-416, 1964.

[4] Hardison, C.H., Storage to augment low flows. Proceedings of Reservoir Yield Symposium. Water Research Association, Oxford: UK, pp. 8, 1965.

[5] Hashimoto, T., Stcdinger, J. R. and Loucks, D. P., Reliability, Resiliency, and Vulnerability Criteria For Water Resource System Performance Evaluation Water Resources Research, 18, pp. 14-20, 1982.

[6] Rippl, W., The capacity of storage reservoirs for water supply. Minutes of Proceedings Institution of Civil Engineers, 71, pp. 270-278, 1883.

[7] Rittima, A. and Vudhivanich, V., Storage-Yield- Resilience-Reliability Relationship of Mun Bon Reservoir. Proceedings of 41st Kasetsart University Annual Conference, Bangkok: Thailand, pp. 55-64, 2003.

[8] Srivastava, D.K., and Awchi, T.A, Storage-Yield Evaluation and Operation of Mula Reservoir, India. Journal of Water Resources Planning and Management, 135(6), pp. 414-425, 2009.

[9] Yi, J. Y. and Song, J. W., Evaluation of Water Supply Capacity for MultiPurpose Dam Using Optimization and Simulation Techniques. Korean Society of Civil Engineers, 22(6-B), pp. 811-818, 2002. 